\title{
A Cross-Cultural Newspaper Content Analysis: Smart Cities in Japanese and Slovenian Newspapers
}

\author{
Yukiko SATO ${ }^{\mathrm{a}, 1}$ and Stefan BRÜCKNER ${ }^{\mathrm{a}, 2}$ and Maja PUŠNIK ${ }^{\mathrm{b}, 3}$ \\ ${ }^{\mathrm{a}}$ Keio University, Graduate School of Media and Governance \\ ${ }^{\mathrm{b}}$ University of Maribor, Faculty of Electrical Engineering and Computer Science
}

\begin{abstract}
The realisation of smart cities has attracted much attention in recent years from private and governmental actors, as a means to make cities more efficient, climate friendly and socially inclusive through the use of modern technology. However, few studies examine how smart cities are framed and understood within the public sphere. The aim of this study is to compare how domestic smart city initiatives are reported in the news of their respective countries, and to clarify the differences and similarities in media content. In this paper, we present the initial findings of our planned long-term comparative news content analysis. As a first step, we analysed national newspaper articles published between 2011 and 2019 in Japan and Slovenia. Our corpus consists of 41 Japanese and 20 Slovenian articles, written in relation to domestic smart city initiatives. In total, we identified 14 themes, five of which were common in both countries, while the remaining nine appeared exclusively in the news of one country. Our conclusions indicate that the news in both countries differ in what application domains of Smart Cities are discussed (e.g. natural resources and energy, transportation and mobility). We establish a procedure for further cross-cultural analyses, necessary to understand how smart cities are framed in the public sphere. Thereby, we contribute to further discussion on the nature and definition of smart cities and how they are communicated.
\end{abstract}

Keywords. Smart cities, news media, cross-cultural, newspaper content analysis, Japan, Slovenia.

\section{Introduction}

According to the United Nations Department of Economic and Social Affairs [1], the urban population in the world has grown rapidly from 751 million in 1950 to 4.2 billion in 2018 . By $2050,68 \%$ of the global population is projected to live in urban areas. In conjunction, the number of cities with more than 10 million inhabitants will increase by ten, from currently 33 to 43 by 2030 . This development brings with it problems, such

${ }^{1}$ Yukiko Sato, Keio University, Graduate School of Media and Governance, Endo 5322 Fujisawa, Kanagawa, 252-0882 Japan; E-mail: yukisato@sfc.keio.ac.jp.

${ }^{2}$ Stefan Brückner, Keio University, Graduate School of Media and Governance, Endo 5322 Fujisawa, Kanagawa, 252-0882 Japan; E-mail: bruckner@sfc.keio.ac.jp.

${ }^{3}$ Maja Pušnik, University of Maribor, Faculty of Electrical Engineering and Computer Science, Koroška cesta46, 2000 Maribor, Slovenia; E-mail: maja.pusnik@um.si. 

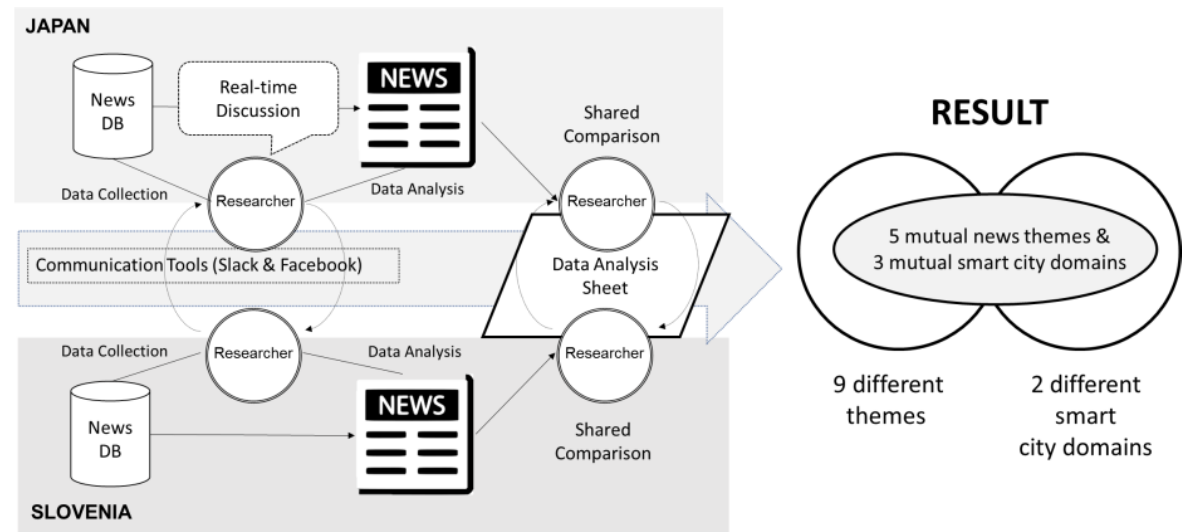

Figure 1. Overview of research design

as insufficient housing capacity and a lack of job opportunities, leading to an increase in poverty. It also poses challenges to inhabitants' health and the environment [2]. To mitigate such challenges, the use of modern Information and Communications Technology (ICT) to design and build economically and socially sustainable "smart cities" has received widespread attention $[3,4]$.

In general, smart cities are presented as a complex and digital ecosystem that includes a network of governmental, academic and business institutions, and citizens; however, a universal definition of smart cities does not exist. Mora and Deakin [5] surmise, "Researchers seem to agree in picturing the smart city as an urban environment in which an ICT-driven approach to urban sustainability is activated". However, the concrete understanding of what constitutes a smart city differs among researchers, governmental institutions, the industry and among citizens [5], and indeed from city to city and country to country [6]. We have, therefore, no clear and concise way to define what exactly smart cities are or how they should be realised. Research on smart cities has, so far, been focused on economic and technological aspects, disregarding the social, cultural and environmental dimensions necessary for ICT-related urban innovation [7].

This study examines how smart cities are portrayed in the public sphere in different localities by analysing Japanese and Slovenian newspaper articles on domestic smart city initiatives (Figure 1). We thereby hope to provide insights into what kind of information on smart cities the general public is exposed to, and how public discussions are shaped in relation to this topic. Citizens themselves are core stakeholders of smart city development, but the public discourse, especially outside Western Europe and the US, has so far been neglected in prior research.

Based on a content analysis of 41 Japanese and 20 Slovenian daily national newspaper articles, we identified 14 thematic structures in articles related to smart cities. Five of those were found in both Japan and Slovenia, while 9 themes were found exclusively in only one of the countries. We also examined which constitutive elements of a smart city were mentioned concretely in each article. The results of this study are the first step towards a systematic examination of the public discourse on smart cities in different localities. Such an examination can provide valuable input into discussions on what does, and what should, constitute smart cities, and on how such concepts are communicated to the public. 


\section{Background}

Since the first publications on the topic in 1992, research into how to realise smart cities has gradually intensified and grown in scope [7]. Research papers related to "smart city" or "smart cities" in academic databases, have increased since the end of the millennium, currently reaching the highest number of research activities in the past two years. Gupta et al. [8] categorized the popular research areas on smart cities. They found that themes such as design and management of smart cities, innovation and technology and citizens' engagenemnt have been extensively studied, while the focus on their social impact on society is moderate. Especially in this field, the lack of a common definition for smart cities is noted by several researchers $[9,10]$. In their literature review, Mora et al. [7] came to the conclusion that researchers generally agree that a smart city is an urban environment utilising an ICT-driven approach to urban sustainability, but also point out thematic and definitional differences between the academic literature [11-13], pursuing a holistic view, and business reports, focusing on the technological dimension of smart cities $[14,15]$. Despite the lack of a common definition of smart cities, researchers have conducted cross-cultural analysis of smart city concepts on the regional and global levels.

On the regional level, Vanolo [16] compares how smart cities are outlined conceptually in policy papers produced by the Italian government and municipalities, to documents from the Commission of the European Union. Similarly, Haarstad [17] conducted a comparative text analysis, focusing on sustainability, in documents from the European Union and Norway. On a global level, Joss et al. [18] analysed documents retrieved on the 27 cities with the highest hit-count for "smart city" world-wide, using co-occurrence and concordance analysis. These approaches showcase a focus on official policy papers to examine the current discourses on smart cities, and are limited to material available in English; however, systematic reviews on how the public conceives smart cities are rarely seen.

Therefore, in this paper, we conduct a comparative content analysis aimed at clarifying how smart cities are framed in the public sphere, by investigating news articles in national newspapers. Newspapers are still a premier source of information for a broad range of people, and highly influential in shaping public discourse. By comparing news articles from two countries, we can draw conclusions on how and what different aspects are seen in smart city discourses across country borders. This paper is envisioned as a first step in a larger project towards a comparative analysis of the discourses on smart cities. The focus on Japan and Slovenia allows us to examine two countries that face similar structural problems, such as an ageing population [19], and have similar incentives towards the realisation of smart cities [20]. The outcomes of this project contribute to further constructive discussions on how smart cities should be communicated to the public.

\section{Method}

In this paper, we present the results of a content analysis of Japanese and Slovenian newspaper articles. Content analysis is a widely used methodological approach for studying (textual or audio-visual) communication artifacts [21]. First, we selected the research subject (i.e. newspaper articles as the primary unit of analysis), and conducted initial analyses by examining a small sub-set of the data. Based on this step, we established the code system for this study and proceeded with the main analysis. Table 1 
depicts the variables we gathered for each article, based on Lynch and Peer's guide to newspaper content analysis [22].

Table 1. Variables for the newspaper content analysis

\begin{tabular}{|l|l|}
\hline Variable Name & Explanation \\
\hline Paper ID & 6-digit abbreviation of newspaper name, date, article number \\
\hline Year & Year of the produced article \\
\hline Month, Date & Month and date of the article \\
\hline Page Number & Page number of the article \\
\hline Section & $\begin{array}{l}\text { Section or theme in which the story appears } \\
\text { (e.g., politics, business, science) }\end{array}$ \\
\hline Source of Story & Author of the article (news service, journalist, reader, unknown) \\
\hline Treatment & $\begin{array}{l}\text { The way in which the news story is written } \\
\text { (general news, feature, opinion, others) }\end{array}$ \\
\hline Main Theme & The most prominent main theme of the article \\
\hline Sub-theme & The main application domain of smart cities focused on in the article \\
\hline No. of Words & The total number of words of the article \\
\hline
\end{tabular}

For the comparison of Japanese and Slovenian articles, we use a dual system of inductive and deductive codes. The inductive codes were developed through a close reading of the text material and discussion in the research team. They were used to signify the overall thematic frame of each article. In addition, we also coded each article based on which application domains of smart cities are discussed within [23]. To identify the application domains, we used the conceptual framework developed based on a literature review by Anthopoulos [24] (see Table 2).

Table 2. Overview of application domains of smart cities, based on [23]

\begin{tabular}{|l|l|}
\hline Application Domain & Example \\
\hline Natural Resources and Energy & $\begin{array}{l}\text { Natural resources, natural environment, energy, smart environment, } \\
\text { water management, waste management }\end{array}$ \\
\hline $\begin{array}{l}\text { Transportation } \\
\text { and Mobility }\end{array}$ & $\begin{array}{l}\text { Mobility, transport, activities, walkability, green transportations, smart } \\
\text { mobility }\end{array}$ \\
\hline Urban Infrastructure & $\begin{array}{l}\text { Buildings, urban planning, architecture, urban design, housing, facility } \\
\text { management }\end{array}$ \\
\hline Living & $\begin{array}{l}\text { Healthcare, safety, security, education, people, density, quality of life, } \\
\text { technology, smart living, entertainment, pollution control, culture, } \\
\text { welfare, hospitality, public spaces`management }\end{array}$ \\
\hline Government & E-government, e-democracy procurement, transparency \\
\hline Economy & $\begin{array}{l}\text { Economy, institutions, urban openness, partnership, smart economy, } \\
\text { cultural heritage management, innovation and entrepreneurship, human } \\
\text { capital management, digital education }\end{array}$ \\
\hline Coherency & Society, social, connectivity, social integration, social connectedness \\
\hline
\end{tabular}

Table 3 depicts the national newspapers from which articles were drawn for this study, the Japanese Asahi Shimbun and Yomiuri Shimbun and the Slovenian Delo and Večer. They were chosen to represent different political leanings. In the first step, we collected all articles published up to December 2019 from the respective databases that included the term "smart city". The first such article was originally published in 2011. 
In the second step, we identified relevant articles that focused thematically on domestic smart city initiatives through close reading.

Table 3. Sources for research

\begin{tabular}{|l|l|l|l|}
\hline \multirow{2}{*}{ Country } & Name & Type/Orientation & $\begin{array}{l}\text { Distributed } \\
\text { (Base) Region }\end{array}$ \\
\hline \multirow{2}{*}{ Japan } & Asahi Shimbun & $\begin{array}{l}\text { National } \\
\text { daily/Liberal }\end{array}$ & All Japan \\
\cline { 2 - 4 } & Yomiuri Shimbun & $\begin{array}{l}\text { National } \\
\text { daily/Conservative }\end{array}$ & All Japan \\
\hline \multirow{2}{*}{ Slovenia } & Delo (Labour) & $\begin{array}{l}\text { National } \\
\text { daily/Liberal }\end{array}$ & All Slovenia \\
\cline { 2 - 4 } & Večer (Evening News) & $\begin{array}{l}\text { National } \\
\text { daily/Conservative }\end{array}$ & All Slovenia \\
\hline
\end{tabular}

\section{Results}

In total, our data set consisted of 61 articles, 41 from Japan (Asahi Shimbun: 20, Yomiuri Shimbun: 21) and 20 from Slovenia (Delo: 10, Većer: 10). In this section, we show the following results from our comparison of Japanese and Slovenian newspaper articles: 1) The number of articles published from 2011 to 2019,2) The distribution of articles in newspaper sections, 3) The type of articles, 4) The distribution of main themes, and 5) The mentioned application domains for smart cities.

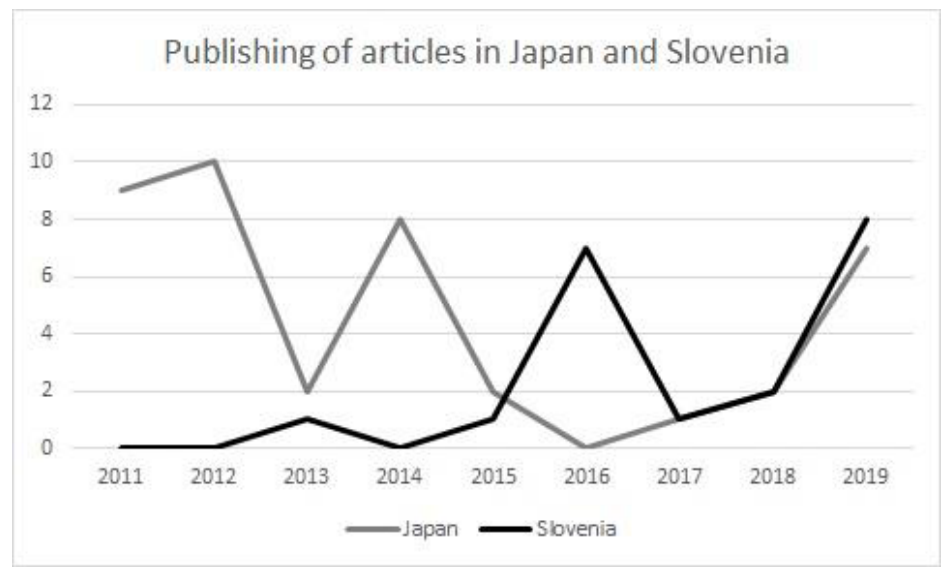

Figure 2. Number of articles from 2011 to 2019

Our findings show that Japanese articles began reporting on domestic smart city initiatives in 2011, while the first Slovenian article dates to 2013. Although the total number of articles per year fluctuated until 2016, a steady rise in the number of articles can be seen in both countries since 2017 (see Figure 2). Japanese articles originally peaked in 2012, while the first Slovenian article was found in 2013, with a peak of seven articles in 2016 and a further growth to 8 in 2019. 
Table 4. Distribution of newspaper articles per section

\begin{tabular}{|l|l|l|l|}
\hline Section & All & Japan & Slovenia \\
\hline Business & 28 & 22 & 6 \\
\hline Special & 14 & 9 & 5 \\
\hline General & 14 & 5 & 9 \\
\hline Politics & 2 & 2 & 0 \\
\hline Opinion & 2 & 2 & 0 \\
\hline Front Page & 1 & 1 & 0 \\
\hline
\end{tabular}

Table 4 shows the distribution of the articles in both countries per newspaper section. 28 (Japan 22, Slovenia 6) of the 61 articles were published in the business section. More than half of all Japanese articles were published here. This was followed by the special section, with nine Japanese and five Slovenian articles respectively, as well as the general section, in which nine of the 20 Slovenian articles were published. The remaining Japanese articles were published in the politics section (2), the opinions section (2) and the front page (1).

Table 5. Distribution of article types

\begin{tabular}{|l|l|l|l|}
\hline Type of Articles & All & Japan & Slovenia \\
\hline News Report & 40 & 28 & 12 \\
\hline Feature Article & 9 & 4 & 5 \\
\hline Opinion Piece & 6 & 3 & 3 \\
\hline Event Report & 6 & 6 & 0 \\
\hline
\end{tabular}

In both the Slovenian and Japanese newspapers, news reports, written by journalists of the respective paper, were the most common form of article found. This was followed by feature articles, which were the second most common type in the Slovenian newspapers, focusing mostly on social problems. Three Japanese and Slovenian articles were opinion pieces on smart city initiatives, written by academics. In Japan, six articles reported on events sponsored by the newspapers involving the discussion of smart city concepts.

Table 6. Comparison of news themes

\begin{tabular}{|l|l|l|l|}
\hline Category & All & Japan & Slovenia \\
\hline Smart City - Business & 24 & 17 & 7 \\
\hline Smart City - Concept & 14 & 6 & 8 \\
\hline Smart City - Development & 4 & 4 & 0 \\
\hline Reconstruction after 3.11 & 4 & 4 & 0 \\
\hline Energy & 3 & 3 & 0 \\
\hline Personal information & 2 & 1 & 1 \\
\hline Artificial Intelligence & 2 & 1 & 1 \\
\hline Foreign Relations & 2 & 1 & 1 \\
\hline Overseas Expansion & 1 & 1 & 0 \\
\hline Society 5.0 Movement & 1 & 1 & 0 \\
\hline Government Project & 1 & 1 & 0 \\
\hline Depopulation & 1 & 1 & 0 \\
\hline Industry 4.0 Concept & 1 & 0 & 1 \\
\hline Smart City - Education & 1 & 0 & 1 \\
\hline
\end{tabular}

A total of 14 thematic categories were identified through the inductive coding analysis of the articles (see Table 6). Five of those were found in Japanese and Slovenian articles, while another seven themes in the Japanese and two in the Slovenian articles 
were exclusive to those countries. Most articles were focused either on smart city initiatives initiated by private corporations (Smart City - Business), or on the general concept, purpose and benefits of smart cities (Smart City - Concept). 38 of the 61 articles fell into one of those categories. However, despite their thematic similarity, the focus of those articles differed between the Japanese and Slovenian newspapers. Japanese articles coded as "Smart City - Business" were mostly announcements of major companies engaging in new smart city ventures, focused predominantly on infrastructure, while articles coded as "Smart City - Concept" tended to discuss the ideal form of smart cities, often in relation to elements of "smart living". In Slovenia, articles labelled as "Smart City - Business" included various concrete efforts of local and foreign companies to invest or support cities and municipalities in Slovenia, while "Smart City - Concept" addressed more abstract strategies of smart cities, discussing whether or not citizens are ready for such solutions, and providing introspective insights into whether they were aware of the benefits.

Although not appearing frequently, concerns regarding the handling of "Personal Information", or expectations towards the use of "AI" in smart cities and how smart city establishment affects "Foreign Relations", were shared in both countries. On the other hand, more reports about the country's own "Smart City Development" projects were evident in Japan, in both liberal and conservative newspapers, whereas the Slovenian media focused more on social issues regarding smart city establishment. In Japan, the progress of the Kashiwa-no-ha smart city initiative in Chiba prefecture, Japan, has been discussed frequently since 2014. Furthermore, the Japanese articles tended to portray the establishment of smart cities as a vision and symbol of hope for the cities affected by the March 2011 earthquake, tsunami and Fukushima nuclear catastrophe. Aside from this, the Japanese articles also reported on governmental initiatives aimed at the realisation of a "Society 5.0" and the "Overseas Expansion" of domestic companies. The realisation of smart cities was also discussed as a possible counter to "Depopulation" in Japan, based on its ageing population. In Slovenia, one further article was focused on "Smart City Education", highlighting successful smart city solutions around the globe and how they can be used to adapt best practices in Slovenia.

Table 7. Comparison of application domains discussed in the articles

\begin{tabular}{|l|l|l|l|}
\hline Domain & All & Japan & Slovenia \\
\hline Natural Resources and Energy & 21 & 21 & 0 \\
\hline Urban Infrastructure & 11 & 11 & 0 \\
\hline Transportation and Mobility & 10 & 1 & 9 \\
\hline Economy & 10 & 1 & 9 \\
\hline Living & 9 & 7 & 2 \\
\hline Government & 0 & 0 & 0 \\
\hline Coherency & 0 & 0 & 0 \\
\hline
\end{tabular}

Table 7 shows what kind of application domains of smart cities the articles focused on. In total, five domains were evident in the examined articles. Out of those, three were present in the articles in both countries, while two were only observed in the Japanese articles. Seven Japanese and two Slovenian articles were sorted into the category "Living", reporting on how smart cities can enhance health, safety and security, through the use of ICT and data management. The domains "Economy" and "Transportation and Mobility" were also observed in both countries, but appeared more frequently in Slovenia, with nine articles each. "Economy" subsumed articles reporting on the economic benefits that investment into smart cities would have on municipalities, while 
"Transportation and Mobility" included articles that mentioned the potential to shorten commuting time in smart cities. In the Japanese newspapers, the most frequently found domain was "Natural resources and energy", again, in relation to the discourse on the 3.11 catastrophe and its implications on energy issues in Japan. This was followed by articles focusing on "Urban Infrastructure", discussing ways to utilise innovative ICT to improve infrastructure.

To summarise our findings, despite their low overall number, articles on smart city initiatives have increased gradually since 2017. The most common form of articles on smart city initiatives was news reports (Japanese newspapers: 68\%, Slovenian: 60\%). Articles were placed in similar sections in both countries, usually business, general news or special feature, although more than half of the Japanese articles were published in the business section (54\%), while Slovenian articles were found most frequently in the general section (45\%). Japan and Slovenia shared the thematic complexes of "Smart City - Business" and "Smart City - Concept", although the former was more prevalent in Japan $(41 \%)$ than in Slovenia (35\%), whereas the latter was more frequently seen in Slovenia (40\%), and less so in Japan (15\%). In the Japanese context, smart cities were often linked to the 3.11 disaster, with $10 \%$ of the articles focusing on reconstruction efforts in the aftermath. The issues of "Artificial Intelligence (AI)", "Personal" information and "Foreign Relations" were discussed in both countries. Comparing the smart city application domains, while Japan showed a focus on "Natural resources and energy" (51\% of the articles), "Industry" (27\%), and "Living" (17\%), "Economy" (45\%) and "Transportation and Mobility" (45\%) were most common in the Slovenian media.

\section{Discussion}

Our examination of Japanese and Slovenian newspaper articles on smart city initiatives revealed similarities in the way smart cities are framed in both countries. Articles were based mainly on information provided by governmental or corporate entities. Smart city initiatives were also not only discussed to improve liveability and sustainability in cities, but also as part of new business opportunities, with chances to partake in increasing revenues [25]. Governmental initiatives on the Internet of Things (IoT), AI, robots and data management are becoming more visible, and are reported on in relation to smart cities, related closely to the Japanese goal of realising "Society 5.0" [26].

The differences in the examined articles can be explained most easily by the differing stages of smart city realisation in both countries. While several projects, such as the "Kashiwa-no-ha Smart City", are currently under development in Japan, spurred by the experience of the 3.11 catastrophe and perceived as an alternative way for the Japanese reconstruction efforts [27,28]. In Slovenia, the articles reflected a different stage of smart city realisation in the country, discussing mostly business opportunities and model cases for the establishment of best practices. While the application domains discussed in Japan are influenced greatly by the 3.11 catastrophe and resulting concerns on energy and sustainability, Slovenia is more focused on benefits to transportation and mobility, aside from concrete business expectations. This reflects the current priorities of the Slovenian government to solve traffic problems and increase people's wellbeing in a sustainable manner [29].

Our analysis suggests that the discourse on smart cities in both countries is currently dominated largely by governmental and industrial actors, highlighting the benefits of such initiatives. This brings with it potential problems in relation to an imbalance of 
information, and an underrepresentation of academic or civil voices in the discourse, that again results in a lack of reports on the application domains "Government" and "Coherency" in the examined articles.

As this comparison of Japanese and Slovenian articles related to the theme of smart cities is a preliminary step in our research, aiming to form the base for our cross-regional comparative newspaper analysis, the numbers of analysed resources are limited. In order to enhance the generalisability of this research, further articles, as well as literature, are planned to be examined. This paper contributes to discovering major diversities in discourses regarding smart cities, as well as providing a cross-cultural analysis foundation for future work.

\section{Conclusion}

In this paper, we examined 61 Japanese and Slovenian newspaper articles on smart city initiatives through a content analysis. We identified 14 thematic complexes, of which five were found in both countries: 1) Smart City - Business, 2) Smart City - Concept, 3) Personal Information, 4) AI and 5) Foreign Relations. Slovenian newspapers tended to focus more on educating the public about smart city initiatives, and discussing potential benefits towards transportation and mobility, while Japanese articles were focused on the business dimension, but also influenced heavily by the 3.11 catastrophe and resulting energy issues.

One motivation for this research was to establish a methodological approach to study newspaper content from a cross-cultural perspective. This paper shows an example of a comparative text analysis conducted across regional and cultural borders between researchers located in different time zones. Through this study, we contribute towards a clearer picture of the underlying structure of current discourses on smart cities, and how their definition and the way they are communicated changes across countries. As these are the first outcomes of our study, the results are still limited by the small number of articles examined. We plan to extend the number of articles for further analysis by including more media outlets into our corpus. In addition, we plan to automate our analysis method, in order to examine large quantities of newspaper data and extract specific aspects in newspaper contents, such as solutions and potential threats towards establishing a Smart City. The development of this automated analysis tool will include semantic technologies of Semantic Web and Natural language processing (NLP).

\section{References}

[1] United Nations Department of Economic and Social Affairs Population Division. World Urbanization Prospects. New York: United Nations. 2019.

[2] National Geographic. Urban Threats. 2019. [Accessed 2019 December 21]. https://www.nationalgeographic.com/environment/habitats/urban-threats/.

[3] Silva BN, Khan M, Han K. Towards Sustainable Smart Cities: A Review of Trends, Architectures, Components, and Open Challenges in Smart Cities. Sustainable Cities and Society. 38 (2018), 697-713.

[4] Arasteh H, Hosseinnezhad V, Loia V, Tommasetti A, Troisi O, Shafie-Khah M, Siano P. Iot-Based Smart Cities: A Survey. Paper presented at: 2016 IEEE 16th International Conference on Environment and Electrical Engineering (EEEIC). IEEE; 2016 June 7-10; Florence, Italy.

[5] Mora L, Deakin M. Untangling Smart Cities: From Utopian Dreams to Innovation Systems for a Technology-Enabled Urban Sustainability. Amsterdam, Netherlands: Elsevier. 2019. 
[6] Smart Cities Mission. What Is Smart City. 2018. [Accessed 2019 December 31]. http://smartcities.gov.in/upload/uploadfiles/files/What\%20is\%20Smart\%20City.pdf.

[7] Mora L, Bolici R, Deakin M. The First Two Decades of Smart-City Research: A Bibliometric Analysis. Journal of Urban Technology. 24 (2017), 3-27.

[8] Gupta P, Chauhan S, Jaiswal M. Classification of Smart City Research-a Descriptive Literature Review and Future Research Agenda. Information Systems Frontiers. 21 (2019), 661-685.

[9] Hollands RG. Will the Real Smart City Please Stand Up? Intelligent, Progressive or Entrepreneurial? City. 12 (2008), 303-320.

[10] Chourabi H, Nam T, Walker S, Gil-Garcia JR, Mellouli S, Nahon K, Pardo TA, Scholl HJ. Understanding Smart Cities: An Integrative Framework. Paper presented at: 2012 45th Hawaii International Conference on System Sciences. IEEE; 2012 January 4-7 Maui, Hawaii.

[11] Caragliu A, Del Bo C, Nijkamp P. Smart Cities in Europe. Journal of Urban Technology. 18 (2011), 6582.

[12] Giffinger R, Fertner C, Kramar H, Meijers E. City-Ranking of European Medium-Sized Cities. Cent Reg Sci Vienna UT. (2007), 1-12.

[13] Schaffers H, Komninos N, Pallot M, Trousse B, Nilsson M, Oliveira A. 2011. Smart Cities and the Future Internet: Towards Cooperation Frameworks for Open Innovation. Paper presented at: The Future Internet Assembly. Springer.

[14] Dirks S, Keeling M. A Vision of Smarter Cities: How Cities Can Lead the Way into a Prosperous and Sustainable Future. New York: USA: IBM. 2009.

[15] Washburn D, Sindhu U, Balaouras S, Dines RA, Hayes N, Nelson LE. Helping Cios Understand "Smart City" Initiatives. Growth. 17 (2009), 1-17.

[16] Vanolo A. Smartmentality: The Smart City as Disciplinary Strategy. Urban Studies. 51 (2014), 883-898.

[17] Haarstad H. Constructing the Sustainable City: Examining the Role of Sustainability in the 'Smart City'discourse. Journal of Environmental Policy \& Planning. 19 (2017), 423-437.

[18] Joss S, Sengers F, Schraven D, Caprotti F, Dayot Y. The Smart City as Global Discourse: Storylines and Critical Junctures across 27 Cities. Journal of Urban Technology. 26 (2019), 3-34.

[19] Daimon S. Slovenia Faces Similar Fiscal Challenges to Japan, Finance Minister Andrej Bertoncelj Says. 2019. [Accessed 2019 December 24]. https://www.japantimes.co.jp/news/2019/06/20/business/slovenia-faces-similar-fiscalchallenges-japan-finance-minister-andrej-bertoncelj-says/\#.XgGnWi3APaY.

[20] Ministry of Foreign Affairs of Japan. Japan-Slovenia Foreign Ministers' Meeting. 2019. [Accessed 2019 December 25]. https://www.mofa.go.jp/erp/c see/si/page6e 000206.html.

[21] Macnamara JR. Media Content Analysis: Its Uses, Benefits and Best Practice Methodology. Asia Pacific Public Relations Journal. 6 (2005).

[22] Lynch S, Peer L. 2002. Analyzing Newspaper Content: A How-to Guide. Readership Institute: Media Management Center at Northwestern University. [accessed 2019 December 25]. https://www.orau.gov/cdcynergy/erc/Content/activeinformation/resources/NewspaperContentA nalysis.pdf.

[23] Neirotti P, De Marco A, Cagliano AC, Mangano G, Scorrano F. Current Trends in Smart City Initiatives: Some Stylised Facts. Cities. 38 (2014), 25-36.

[24] Anthopoulos LG. Understanding the Smart City Domain: A Literature Review. Transforming City Governments for Successful Smart Cities. Springer. p. 9-21. 2015.

[25] Maddox T. Smart City Iot Revenue to Explode from $\$ 25 b$ to $\$ 62 b$ in 2026. 2018. [Accessed 2020 Janurary 4]. https://www.techrepublic.com/article/smart-city-iot-revenue-to-explode-from-25bto-62b-in-2026/.

[26] Cabinet Office Government of Japan. Society 5.0. 2019. [Accessed 2019 December 25]. https://www8.cao.go.jp/cstp/society5_0/index.html.

[27] Mitsui Fudosan. Kashiwa-No-Ha Smart City. 2014. [Accessed 2020 January 4]. https://www.kashiwanoha-smartcity.com/en/concept/whatssmartcity.html.

[28] Tsuchiya Y, Nakabayashi I, Otagiri R. Current Conditions and Issues of Reconstructed-Type Smart City in Disaster Area of the Great East Japan Earthquake. Paper presented at: Institute of Social Safety Science. 2016 November 4-5; Shizuoka, Japan.

[29] European Commission. Smat Specialisation Platform: Slovenia. 2018. [Accessed 2020 Janurary 10]. https://s3platform.jrc.ec.europa.eu/regions/SI. 